\title{
Distance Learning in the COVID-19 Era: Perceptions in Southern Italy
}

\author{
Francesco Vincenzo Ferraro ${ }^{1, *(\mathbb{C})}$, Ferdinando Ivano Ambra ${ }^{2}$, Luigi Aruta ${ }^{2}$ and \\ Maria Luisa Iavarone ${ }^{2}$ \\ 1 Department of Health and Social Science, Bournemouth University, Bournemouth BH125BB, UK \\ 2 Dipartimento di Scienze Motorie e del Benessere, Università degli studi di Napoli Parthenope, \\ 80133 Naples, Italy; ivano.ambra@uniparthenope.it (F.I.A.); lu.aruta@gmail.com (L.A.); \\ marialuisa.iavarone@uniparthenope.it (M.L.I.) \\ * Correspondence: fferraro@bournemouth.ac.uk
}

Received: 11 November 2020; Accepted: 25 November 2020; Published: 27 November 2020

\begin{abstract}
The first case of pneumonia was reported on 8 December 2019 and identified on 7 January 2020 as COVID-19. On 9 March 2020, to stop the spread of COVID-19 cases, the Italian government declared a health emergency, forcing all citizens to go into lockdown. Suddenly, schools were constrained to using distance learning strategies with little or limited experience on the topic. Particularly, in the southern regions of Italy, approximately $20 \%$ of the students did not have access to any devices and were excluded from learning, producing a direct risk of increased adolescent delinquency. This research team intended to report the results of an observational study that focused on the perceptions of distance learning in adolescents from secondary school in Naples (Italy) between April and May 2020. The questionnaire comprised 11 questions focused on the perceptions of distance learning in comparison to live classrooms, relationships with peers and teachers, and levels of anxiety. The study is amongst the first to report the effect of the pandemic from a student-centred perspective and hopes to produce information to develop future research on asynchronous learning.
\end{abstract}

Keywords: pedagogy; sport science; transdisciplinary; childhood learning; technologies; relationship; civil education approach; distance learning; COVID-19; education

\section{Introduction}

The first case of pneumonia was reported on 8 December 2019 and identified on 7 January 2020 as COVID-19 [1]. In less than two months, COVID-19 has reached almost every corner of the world, becoming the most reported and known pandemic in history [2]. The effects upon the economy [3], health system [4], and life in general [5] are known and documented. However, our interest was to investigate the perceptions of the pandemic restrictions from the perspective of adolescents, particularly in relation to distance learning. Distance learning is a mode of teaching and learning that was already available before the pandemic. Generally, learning can be synchronous, involving students learning together in a live environment (e.g., classrooms), which allows greater engagement and a higher sense of community. On the contrary, asynchronous learning allows students to learn on their own using email or online platforms [6]. On this matter, many theories have been reported investigating the most effective ways to create online learning platforms [7]. However, all such theories seem to conclude that the students involved in asynchronous courses need to be extremely self-motivated to learn and need to have a high level of self-discipline to complete courses [8]. To help draw new methods of interaction with students, a recent article in Nature described helpful tips about the transition from synchronous to asynchronous leaning in the COVID-19 era, underscoring the importance of adopting a student-centred approach $[9,10]$. 
On 9 March 2020, to stop the spread of COVID-19 cases, the Italian government declared a health emergency, forcing all citizens to go into lockdown [11]. Following this, schools were constrained to using distance learning strategies, with little or limited experience on the topic [12]. The whole situation produced a significant negative impact on students, with an increase in the number of cases of mental distress [13], with spikes in depression, anxiety, and stress cases [14,15]. The Italian National Institute of Statistics (ISTAT; www.istat.it) reported that $45 \%$ of youths (between 6 to 17 years old) had difficulties coping with distance learning due to a lack of devices (such as a computer or smartphone) in their houses. This particularly affected the southern regions of Italy, where $20 \%$ of students did not have access to any devices and were excluded from learning, producing a direct risk of an increase in adolescent delinquency [16]. We previously demonstrated that the usage of technologies plays a crucial role in educational development in childhood [16-20]. In particular, our most recent publication using the S.M.A.R.T. questionnaire [21] showed that female adolescents have a more conscious use of technology compared to their male peers [22]. Our observational study showed that females use technology to a lesser extent and have a higher self-awareness of the information that can be transferred over social media [22]. We considered this to be related to the potential influence of parental control [23] over the female population. As summarised in a recent meta-analysis, gender-differentiated parental control in child behaviour is driven by gendered stereotypes [24], which might explain why the female group resulted in more awareness of technology usage than the male group. These aspects are extremely significant considering the direct effects of technology on adolescents' behaviours [25] and how abusive use of digital devices can have an effect on learning capacity [26] and social skills in youths [27-30].

With the recent lockdown in Italy, students were forced to adopt novel distance learning strategies via digital communication software (such as CISCO, Zoom, Skype, and Microsoft TEAMS) [31]. During this period of time, the transdisciplinary research team from the University of Naples Parthenope and Bournemouth University, under the supervision of Prof. Iavarone, developed a questionnaire concerning the perceptions of distance learning among young students (13-19 years old). The questionnaire was developed to report students' perceptions of the use of distance learning compared to standard (in class) lessons. The full questionnaire has already been published [32] and preliminary data have been discussed [33]. This research team intended to report the full pooled data collected over the lockdown period in Italy, as this information can be beneficial for future research and discussion regarding learning strategies to adopt in a period of crisis, such as the one we are currently living. Based on our previous findings with the S.M.A.R.T. questionnaire [22], we hypothesised that usage of technology in distance learning by females would show a higher level of adaptability and would benefit mostly from novel digital pedagogic tools. The overall aim was also to report the analysis of the full set of data collected over the lockdown period in Italy as this information can be beneficial for future research and discussion regarding learning strategies to adopt in period of crisis, such as the one we are currently living.

\section{Materials and Methods}

\subsection{General Design}

This observational study was created to report the perceptions of distance learning in adolescents from secondary schools in Naples (Italy) during the recent lockdown. The questionnaire comprised 11 questions on the perceptions and usage of distance learning. The questionnaire has been fully published already in [32] and the preliminary data have been presented [33].

\subsection{Participant Characteristics}

A group of 83 adolescents (descriptive data: 64 females (F), 19 males (M); age $16.3 \pm 2.7$ years) completed the online questionnaire between April and May 2020. To include a broad sample of adolescents, non-specific inclusion/exclusion criteria were selected. Due to the lockdown restrictions, 
the questionnaire was delivered on an online platform (www.surveymonkey.com) [34] via email and social media (i.e., Twitter, Facebook, and WhatsApp). Data were anonymised and collected according to the guidelines of the 1975 Declaration of Helsinki, revised in 2013.

\subsection{Data Analysis}

The aim of this manuscript was to report the full pooled data analysis collected over the lockdown period in Italy, as this information can be beneficial for future research and discussion regarding learning strategies to adopt in a period of crisis, such as the one we are currently living. Based on our previous findings from the S.M.A.R.T. questionnaire [22], we hypothesised that during distance learning, females would show a higher level of adaptability and would benefit mostly from the novel digital pedagogic tools. Hence, a quantitative approach was used, and the data were grouped by gender, and the descriptive analysis reported the characteristics of our cohort. The Shapiro-Wilk Test was used to address normality, and since the data were not normally distributed, to test the effects of gender in the participants' responses, a Mann-Whitney $U$ test was used. The threshold for statistical significance was determined a priori as $p \leq 0.05$. Data are reported as mean and standard deviation. The analysis was completed with IBM SPSS 26 software.

\section{Results}

A total of 83 students $(16.3 \pm 2.7$ years old) completed the questionnaire (19 M and $64 \mathrm{~F})$. No significant differences in gender ( $\mathrm{M}$ vs. F; $p>0.05$ ) were reported in the answers. To describe the characteristics of the students during the lockdown, we asked the students to complete questions in relation to the software that was used, the location where they followed classes, if they were multitasking (i.e., using other devices while following the lessons such as surfing on social media), and the amount of hours they were actually in virtual classes. The descriptive data are reported in Table 1.

Table 1. Descriptive characteristics of the 83 students ( $16.3 \pm 2.7$ years old) undergoing distance learning during the 2020 lockdown in southern Italy.

\begin{tabular}{cc}
\hline Software & Percentage \\
\hline Google & $26.5 \%$ \\
Zoom & $25.3 \%$ \\
Other & $20.5 \%$ \\
Skype & $19.3 \%$ \\
Microsoft Teams & $6.0 \%$ \\
CISCO & $2.4 \%$ \\
\hline Location & Percentage \\
\hline Own room & $68.7 \%$ \\
Different room & $30.1 \%$ \\
\hline Device & Percentage \\
\hline Computer & $43.4 \%$ \\
Smartphone/tablet & $56.5 \%$ \\
\hline Multitasking & Percentage \\
\hline Yes & $95.2 \%$ \\
No & $4.8 \%$ \\
\hline
\end{tabular}

The students also reported that they had followed between 1 and 11 lesson per week for $1-8 \mathrm{~h}$ per day. The percentages reported in Table 2. 
Table 2. Descriptive characteristic of number of classes and hour of lessons followed by the students expressed in percentage.

\begin{tabular}{cccc}
\hline Classes $(\boldsymbol{n})$ & Percentage & Hours of Lessons (h) & Percentage \\
\hline 1 & 1.2 & 1 & 3.6 \\
2 & 0.0 & 2 & 10.8 \\
3 & 0.0 & 3 & 42.2 \\
4 & 7.2 & 4 & 34.9 \\
5 & 14.5 & 5 & 20.5 \\
6 & 20.5 & 6 & 1.2 \\
7 & 24.1 & 7 & 0.0 \\
8 & 24.1 & 8 & 2.4 \\
9 & 8.4 & & \\
10 & 1.2 & & \\
11 & 7.2 & & \\
\hline
\end{tabular}

The data on the perceptions of distance learning between males and females are reported in Figure 1.

A Overal experiences with DL compare to in class lessons....

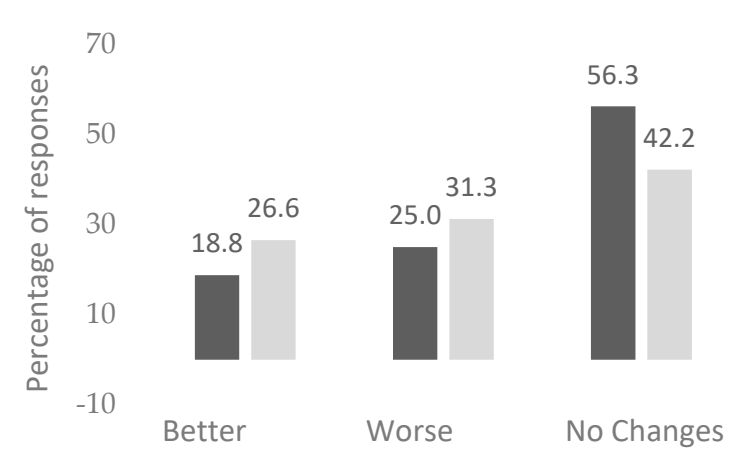

- Male Female

C I experienced overall learning...

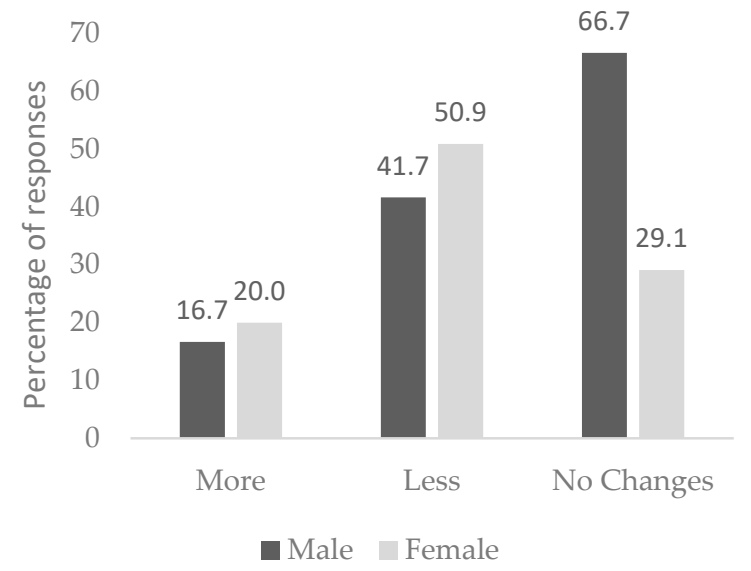

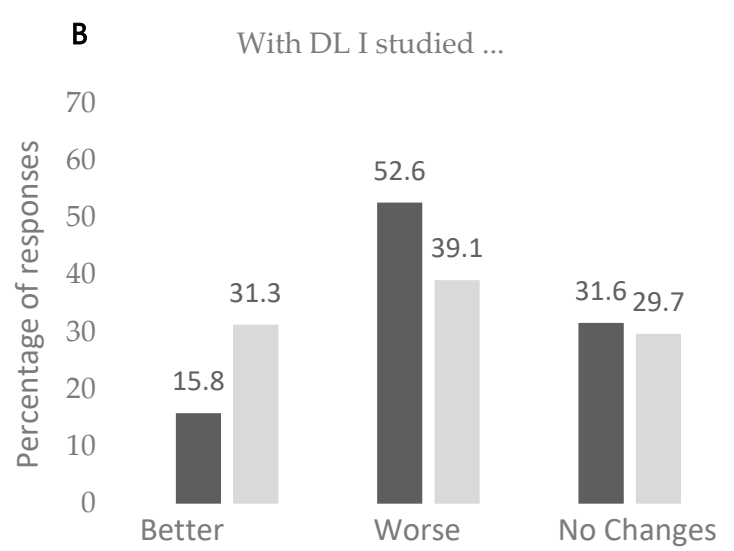

- Male Female

D

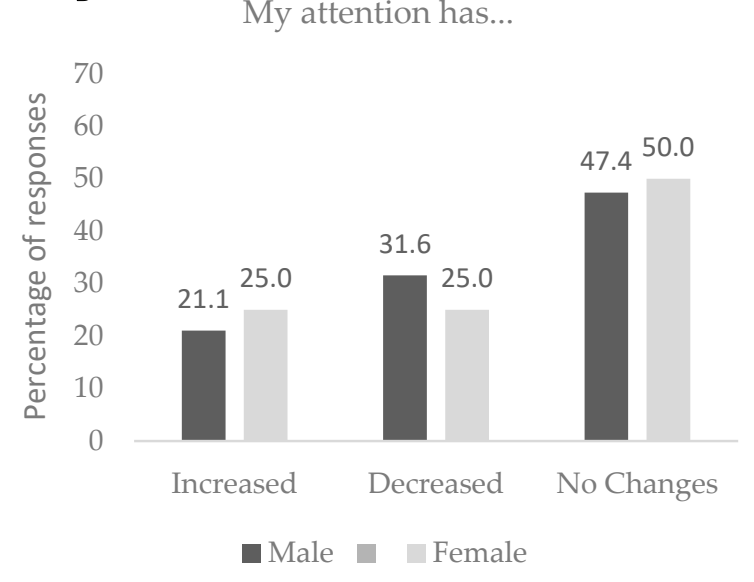

Figure 1. Perceptions of distance learning in males and females based on: (A) Overall experience of distance learning compared to standard classrooms; (B) study perceptions during distance learning; (C) overall learning experience; (D) level of attention.

The data on the relationships with peers during distance learning between males and females are reported in Figure 2. 

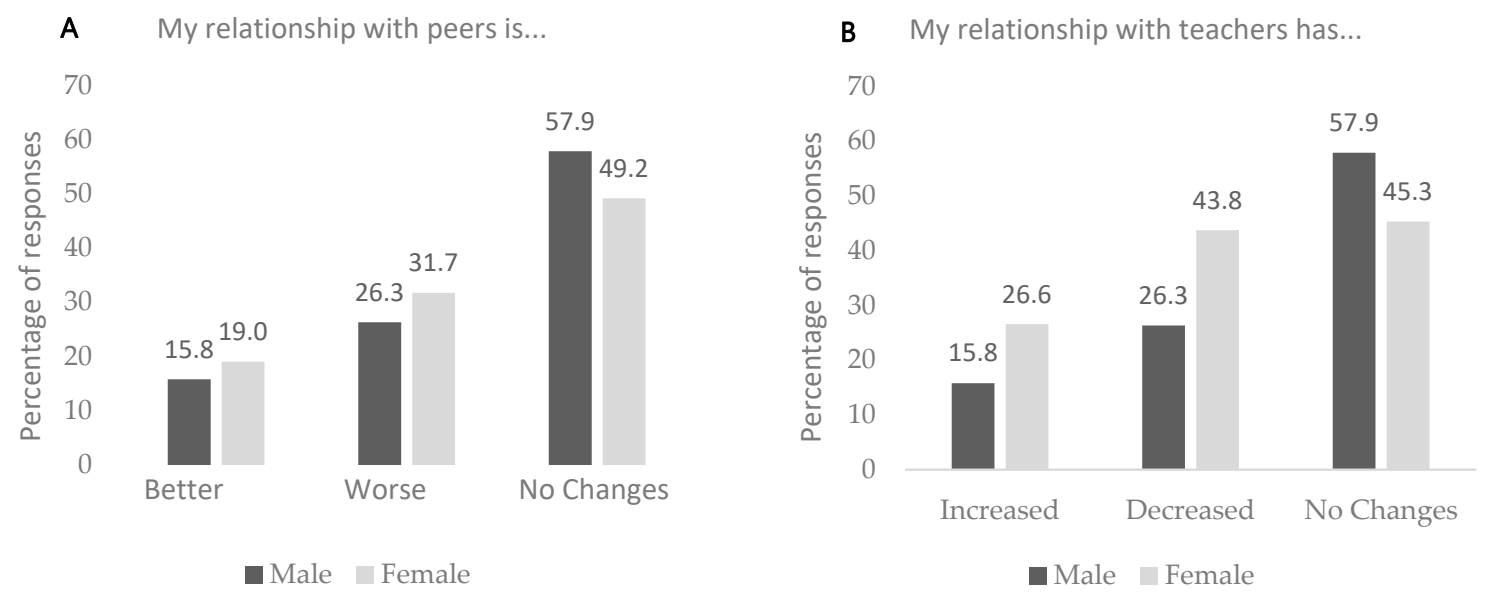

Figure 2. Effect of distance learning on relationships with peers (A) and teachers (B) between males and females.

The levels of anxiety and stress perceived are reported in Figure 3.

After lessons, I feel...

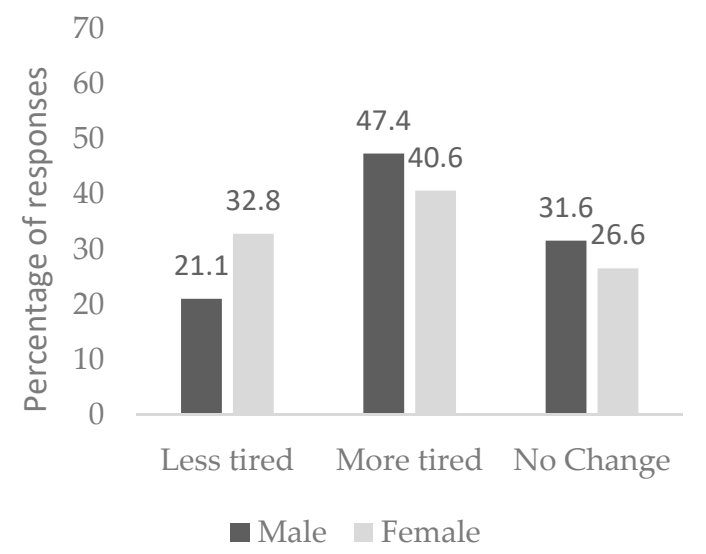

(A)

During lessons, I feel...

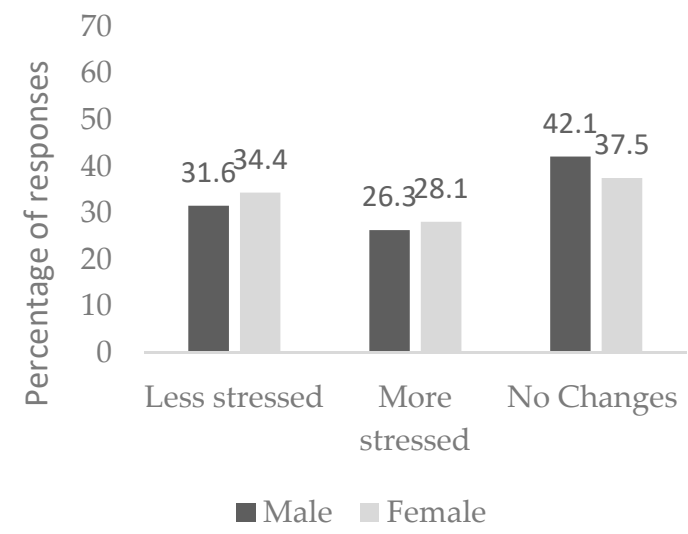

(C)
During lessons, I feel...

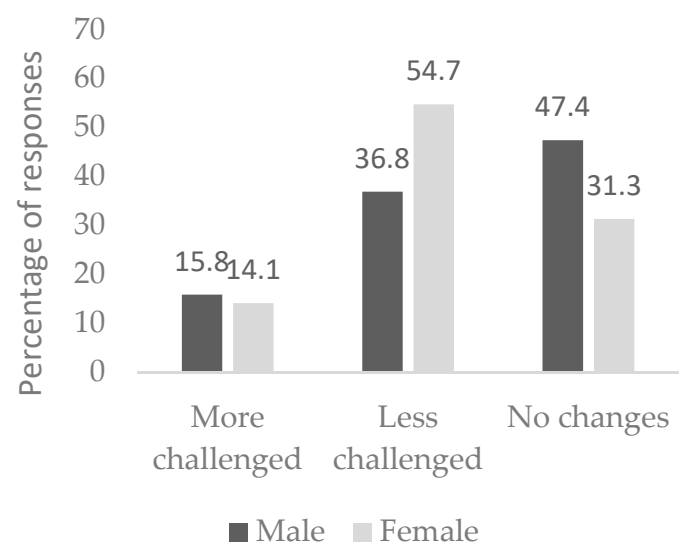

(B)

Homework anxiety has...

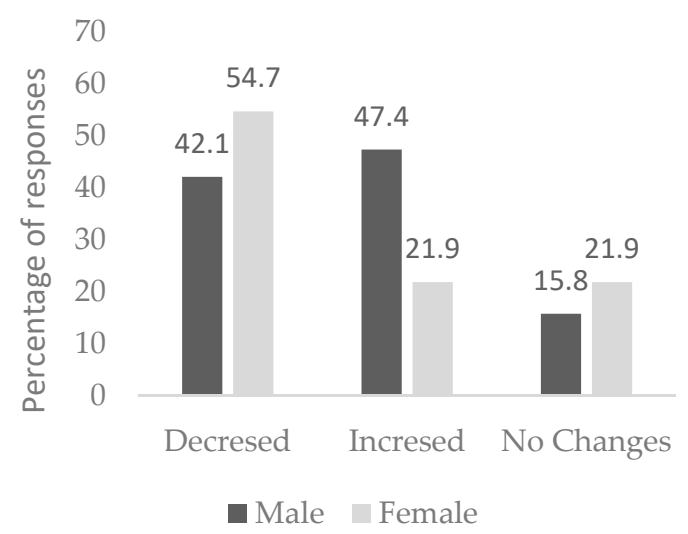

(D)

Figure 3. Perceptions of anxiety and mental stress between males and females after lessons (A), during lessons (B,C), and during homework (D). 


\section{Discussion}

This observational study was carried out to report and explore the perceptions of distance learning in adolescents from secondary schools in Naples (Italy) during the recent lockdown. The questionnaire comprised 11 questions on the perceptions and usage of distance learning. It has already been fully published [32] and preliminary data have been presented [33]. The research team delivered the questionnaire between April and May 2020, with the lockdown restrictions starting in March. The overall questionnaire explored three main areas of pedagogic interest: (i) The perceptions of distance learning, (ii) the relationships with peers and teachers, and (iiii) the levels of stress and anxiety. Our cohort of 83 students showed no differences between gender, which shows common perceptions along males and females. These data could have been predicted based on previous findings [22]. However, we anticipated that the female group might have had a higher level of parental control regarding the usage of technologies, as demonstrated in previous studies $[23,35,36]$. Thus, it seems that when it comes to distance learning, the effect of parental control is no longer applicable and males and females perceived the experience similarly. Further studies should produce a questionnaire tailored to adults and tutors in order to report the effects of stereotypes and parental control and the limitations on the use of technologies that different groups (social, gender, and cultural groups) might experience.

Relationship with peers and teachers showed a tendency to be perceived as identical to what it was before the lockdown (i.e., in class sessions). These results show two important aspects of distance learning. First, the new generation of digital natives, defined as hyper-cognitive generation [37], is able to interact with peers via social media platforms (e.g., TikTok, Facebook, Twitter, and Snapchat) in more efficient ways than previous generations $[38,39]$. Social media relationships have changed the way adolescents interact. Previous research, before the lockdown, documented that there is an increase of social media interactions with peers in contrast with a less in-person interaction [40]. However, even if social media platforms might produce benefits in relation to adolescents' loneliness [41], there are many other aspects, such as body perceptions and sexualised behaviours, that require further investigation and monitoring by adults and tutors [42]. The second important aspect to consider concerns the relationships with teachers. As described in other research, the new generation has replaced "communication" with "interaction" [43], forcing teachers to create classroom setups that incorporate new technologies into their classrooms [44]. These aspects are extremely interesting when we look at the results on multitasking. In our cohort, $95.2 \%$ of the students admitted having used other devices and surfing the web while they were following distance learning classes. Further research should now investigate the effect of multitasking on leaning in the younger generation. In line with recent pedagogic exploration that introduced the concept of multiplexing rather than multitasking, it is possible to develop conditions that make written interaction through social media beneficial to education [45].

Levels of anxiety and stress were also included in our questionnaire. Our data showed a tendency toward diminishing anxiety levels in relation to homework. Anxiety is a major concern when it comes to education, affecting learning and teaching outcomes [46]. Previous research has shown that student anxiety decreases during active-learning activities and when multiple ways of learning opportunities are provided [47]. The situation of lockdown experienced between March and May 2020 might therefore have favoured a more student-centred approach [48] in contrast to a teacher-centred approach [49,50]. As anticipated in the introduction, to cope with distance learning difficulties, teachers need to increase their interaction with students that promote the transition from synchronous to asynchronous learning, helping students to increase collaboration (even if virtually) and critical thinking. Indeed, as reported by the structural equation modelling in Kember's study (2008), the teaching environment should favour teacher-student and student-student relationships to increase intellectual aspects (e.g., critical and creative thinking), as well as collaboration (e.g., communication and interpersonal skills) [51].

These preliminary results need to be considered also in parallel with recent findings from the Italian Educational Research Society (SIRD) who recently conducted an investigation into the experience of 
Italian teachers during the COVID-19 pandemic. In particular, the SIRD reported information on the organisational strategies and teaching methods adopted during the lockdown [52].

\section{Conclusions and Limitations}

In conclusion our research produced the following take-home points. First, there were no gender differences in the perceptions of distance learning, indicating a transversal effect of asynchronised teaching upon our cohort. Secondly, the importance of student-student and student-peer relationships. Regardless of the distance created by asynchronised learning, the students did not perceive a decrease in their relationships with peers or with teachers. This indicates an incredible resilience and ability to deal with technology never seen before in previous generations. Third is the level of anxiety, as it seems that asynchronised learning might be beneficial in decreasing the level of anxiety is some students, particularly in relation to homework.

The COVID-19 pandemic is still present in our lives, where schools continue to be closed every time a student tests positive for COVID-19. Thus, there are further aspects that need to be evaluated; further analysis should investigate in more detail the parental control regarding the use of technology, especially to anticipate and predict information concerning stereotyped parental control (e.g., gender, social, and cultural differences). Additionally, we recommend a broad analysis concerning relationships with peers using social media to define what can be defined as a healthy social media relationship and what is not. There are many types of interactions that take place via novel apps (e.g., Facebook and TikTok) that especially need additional monitoring to prevent phenomena such as unhealthy body perceptions and sexualised behaviours.

Further research should also report details about anxiety levels during asynchronised teaching and how to increase the quality of students' experiences during a dramatic situation such as the recent lockdown. We also reported the vast use of multiplexing. Research is necessary to investigate the effect of multiplexing in the younger generation and how this phenomenon can be integrated as a pedagogic tool. In conclusion, we aimed to report the perceptions of distance learning during the Italian lockdown in a cohort of young students. We focused on three main aspects: Learning, relationships, and anxiety. Distance learning has many downsides, one of which is the lack of live participation, which is an important aspect of social pedagogy [16-18,20], particularly in relation to the evident lack of inclusive activities (such as sport practices). As suggested [53], it is now important to help adolescents that are going through these difficult times. We can do this by being responsive adults [16], setting an example for the younger generations, that for the first time have to deal with self-managing their learning experiences, which require both distance and live assistance.

The are several limitations to our analysis. First is the lack of a hypothesis to drive a strong statistical analysis. The lack of a hypothesis was due to lack of information concerning the current DL in the southern regions of Italy and the perceptions and coping strategies that students have developed regarding DL. Another limitation is the lack of detail in relation to teachers' strategies in southern Italy. As anticipated, a very recent report was completed by SIRD that describes information about the organisational strategies and teaching methods adopted during the lockdown [52]. We recommend combining these finding with student perceptions in order to produce a parallel pool of data on lockdown DL strategies.

Author Contributions: Conceptualization, F.V.F. and F.I.A.; methodology, F.V.F. and F.I.A.; validation, F.V.F., F.I.A. and M.L.I.; formal analysis, F.V.F.; investigation, F.I.A. and L.A.; resources, F.V.F.; data curation, F.V.F.; writing-original draft preparation, F.V.F.; writing—review and editing, M.L.I., F.I.A. and L.A.; visualization, F.V.F.; supervision, M.L.I.; project administration, F.I.A. and L.A.; funding acquisition, F.V.F., F.I.A. and M.L.I. All authors have read and agreed to the published version of the manuscript

Funding: This research received no external funding.

Acknowledgments: The authors would like to thank all of the participants who took their time to take part in this research.

Conflicts of Interest: The authors declare no conflict of interest. 


\section{References}

1. Wu, Z.; McGoogan, J.M. Characteristics of and important lessons from the coronavirus disease 2019 (COVID-19) outbreak in China: Summary of a report of 72314 cases from the Chinese Center for Disease Control and Prevention. JAMA 2020, 323, 1239-1242. [CrossRef] [PubMed]

2. Velavan, T.P.; Meyer, C.G. The COVID-19 epidemic. Trop. Med. Int. Health 2020, 25, 278. [CrossRef] [PubMed]

3. Baldwin, R.; Weder di Mauro, B. Economics in the Time of COVID-19; CEPR Press: London, UK, 2020.

4. Armocida, B.; Formenti, B.; Ussai, S.; Palestra, F.; Missoni, E. The Italian health system and the COVID-19 challenge. Lancet Public Health 2020, 5, e253. [CrossRef]

5. Pfefferbaum, B.; North, C.S. Mental health and the Covid-19 pandemic. N. Engl. J. Med. 2020, 383, 510-512. [CrossRef]

6. Chen, E.; Kaczmarek, K.; Ohyama, H. Student perceptions of distance learning strategies during COVID-19. J. Dent. Edu. 2020, 1-2. [CrossRef]

7. Cook, D.A.; Dupras, D.M. A practical guide to developing effective web-based learning. J. Gen. Intern. Med. 2004, 19, 698-707. [CrossRef]

8. Clark, J.T. Distance Education. In Clinical Engineering Handbook; Elsevier: Amsterdam, The Netherlands, 2020; pp. 410-415.

9. Gibbs, G. Teaching Students to Learn: A Student-Centered Approach. Available online: https://www. scirp.org/(S(i43dyn45teexjx455qlt3d2q))/reference/ReferencesPapers.aspx?ReferenceID=478920 (accessed on 27 November 2020).

10. Zibers, B.; Estes, J.S. Creating a Virtual Reality Lab: Using a Student-Centered Approach. In Current and Prospective Applications of Virtual Reality in Higher Education; IGI Global: Pennsylvania, PA, USA, 2020; pp. 145-169.

11. Rossi, R.; Socci, V.; Talevi, D.; Mensi, S.; Niolu, C.; Pacitti, F.; Di Marco, A.; Rossi, A.; Siracusano, A.; Di Lorenzo, G. COVID-19 pandemic and lockdown measures impact on mental health among the general population in Italy. Front. Psychiatry 2020, 11, 790. [CrossRef]

12. Pellegrini, M.; Maltinti, C. 'School Never Stops': Measures and Experience in Italian Schools during the COVID-19 Lockdown. Best Evid. Chin. Educ. 2020, 5, 649-663. [CrossRef]

13. Pisano, L.; Galimi, D.; Cerniglia, L. A Qualitative Report on Exploratory Data on the Possible Emotional/Behavioral Correlates of Covid-19 Lockdown in 4-10 Years Children in Italy. Available online: https://psyarxiv.com/stwbn/ (accessed on 27 November 2020).

14. Lakhan, R.; Agrawal, A.; Sharma, M. Prevalence of Depression, Anxiety, and Stress during COVID-19 Pandemic. J. Neurosci. Rural Pract. 2020, 11, 519. [CrossRef]

15. Sher, L. The impact of the COVID-19 pandemic on suicide rates. QJM Int. J. Med. 2020, 113, 707-712. [CrossRef]

16. Iavarone, M.L.; Trocchia, N. Il Coraggio Delle Cicatrici: Storia Di Mio Figlio Arturo E Della Nostra Lotta; Utet: Milan, Italy, 2020.

17. Iavarone, M.L.; Iavarone, T. Pedagogia del Benessere. Per Una Professionalità Educativa in Ambito Psico-Socio-Sanitario. 2004. Available online: https://sites.google.com/site/quitchiwcapitor3/9788846457677-71nestfrunGEhaulu50 (accessed on 27 November 2020).

18. Iavarone, M.L. Alta Formazione Per Lo Sviluppo Educativo Locale. 2009. Available online: https://www.amazon. com/Alta-formazione-sviluppo-educativo-locale-ebook/dp/B007QQHS1A (accessed on 27 November 2020).

19. Pierluigi, M.; Maria, L.I.; Luigina, M.; Teresa, G.; Maria, G.R.; Roberto, F.; Milena, S.; Lucia, C.C.; Loiodice, I.; Massimiliano, F. Landascape education as italian contribution to the implementation of the Agenda 2030. Pedagogia OGGI 2018, 1, 259-276. Available online: https://fair.unifg.it/handle/11369/370309? mode=full.699\# .X8CWS-cRU2w (accessed on 27 November 2020).

20. Iavarone, M.L. Curare i margini. Riprendersi il senso dell'educazione per prevenire il rischio. Annali Online Della Didattica Della Formazione Docente 2019, 11, 1-5.

21. Ambra, F.I.; Ferraro, F.V.; Ferra, V.; Basile, S.; Girardi, F.; Menafro, M.; Iavarone, M.L.; Napoli, A.S.L.A.; Centro, N.O.d.N. Impact of sport training on healthy behavior in a group of 108 adolescents: A pilot study using SMART questionnaire. Well-being Educ. Syst. 2019, 1, 43-47.

22. Ferraro, F.V.; Ambra, F.I.; Iavarone, M.L. Evaluation of Health-Habits with the S.M.A.R.T. Questionnaire: An Observational Study. Educ. Sci. 2020, 10, 285. [CrossRef] 
23. Landry, M.; Turner, M.; Vyas, A.; Wood, S. Social Media and Sexual Behavior Among Adolescents: Is there a link? JMIR Public Health Surveill. 2017, 3, e28. [CrossRef] [PubMed]

24. Endendijk, J.J.; Groeneveld, M.G.; Bakermans-Kranenburg, M.J.; Mesman, J. Gender-Differentiated Parenting Revisited: Meta-Analysis Reveals Very Few Differences in Parental Control of Boys and Girls. PLoS ONE 2016, 11, e0159193. [CrossRef]

25. Stonard, K.E. Technology-assisted adolescent dating violence and abuse: A factor analysis of the nature of electronic communication technology used across twelve types of abusive and controlling behaviour. J. Child Fam. Stud. 2019, 28, 105-115. [CrossRef]

26. Gao, J.; Zheng, P.; Jia, Y.; Chen, H.; Mao, Y.; Chen, S.; Wang, Y.; Fu, H.; Dai, J. Mental health problems and social media exposure during COVID-19 outbreak. PLOS ONE 2020, 15, e0231924. [CrossRef]

27. Sarabia, I.; Estévez, A. Sexualized behaviors on Facebook. Comput. Hum. Behav. 2016, 61, 219-226. [CrossRef]

28. Peris, M.; de la Barrera, U.; Schoeps, K.; Montoya-Castilla, I. Psychological risk factors that predict social networking and internet addiction in adolescents. Int. J. Environ. Res. Public Health 2020, 17, 4598. [CrossRef]

29. Frost, R.L.; Rickwood, D.J. A systematic review of the mental health outcomes associated with Facebook use. Comput. Hum. Behav. 2017, 76, 576-600. [CrossRef]

30. Leena, K.; Tomi, L.; Arja, R. Intensity of mobile phone use and health compromising behaviours-How is information and communication technology connected to health-related lifestyle in adolescence? J. Adolesc. 2005, 28, 35-47. [CrossRef] [PubMed]

31. Crawford, J.; Butler-Henderson, K.; Rudolph, J.; Malkawi, B.; Glowatz, M.; Burton, R.; Magni, P.; Lam, S. COVID-19: 20 countries' higher education intra-period digital pedagogy responses. J. Appl. Learn. Teach. 2020, 3, 1-20.

32. Ambra, F.I.; Ferraro, .F.V.; Girardi, F.; Iavarone, M.I. Distanced learning between educational and technological barriers: A survey in the Campania Region (Italy) with secondary school students. Attual. Pedagog. Dec. 2020.

33. Ambra, F.I.; Ferraro, .F.V.; Girardi, F.; Iavarone, M.I. Towards a teaching that reduces the distance: First results of a survey of the effects of distance learning on secondary school students. Excell. Innov. Teach. Learn. 2020. under review.

34. Symonds, E. A practical application of SurveyMonkey as a remote usability-testing tool. Library Hi Tech 2011, 29, 436-445. [CrossRef]

35. Mulya, A.P.; Lukman, M.; Yani, D.I. Correlation of Media and Parents Role to Adolescent Sexual Behavior. J. Nurs. Care 2020, 3. Available online: http://jurnal.unpad.ac.id/jnc/article/download/26747/13868 (accessed on 27 November 2020).

36. Mayhew, A.; Weigle, P. Media engagement and identity formation among minority youth. Child Adolesc. Psychiatr. Clin. 2018, 27, 269-285. [CrossRef]

37. Hernandez-de-Menendez, M.; Díaz, C.A.E.; Morales-Menendez, R. Educational experiences with Generation, Z. Int. J. Interact. Des. Manuf. (IJIDeM) 2020, 14, 847-859. [CrossRef]

38. Strauss, W.; Howe, N. Generations: The History of America's Future, 1584-2069; William Morrow: New York, NY, USA, 1991.

39. PrakashYadav, G.; Rai, J. The Generation $Z$ and their social media usage: A review and a research outline. Glob. J. Enterp. Inf. Syst. 2017, 9, 110-116.

40. Twenge, J.M.; Spitzberg, B.H.; Campbell, W.K. Less in-person social interaction with peers among US adolescents in the 21st century and links to loneliness. J. Soc. Pers. Relatsh. 2019, 36, 1892-1913. [CrossRef]

41. Thomas, L.; Orme, E.; Kerrigan, F. Student loneliness: The role of social media through life transitions. Comput. Educ. 2020, 146, 103754. [CrossRef]

42. Rajamohan, S.; Bennett, E.; Tedone, D. The hazards and benefits of social media use in adolescents. Nursing 2019, 49, 52-56. [CrossRef] [PubMed]

43. Cilliers, E.J. The challenge of teaching generation Z. PEOPLE Int. J. Soc. Sci. 2017, 3, 188-198. [CrossRef]

44. Lenihan, A. Investigating language policy in social media: Translation practices on Facebook. In The Language of Social Media; Springer: Berlin/Heidelberg, Germany, 2014; pp. 208-227.

45. Tække, J.; Paulsen, M. Distraction and digital media: Multiplexing, not multitasking in the classroom. Læring Og Medier 2019, 21, 1-14.

46. Posselt, J.R.; Lipson, S.K. Competition, anxiety, and depression in the college classroom: Variations by student identity and field of study. J. Coll. Stud. Dev. 2016, 57, 973-989. [CrossRef] 
47. Downing, V.R.; Cooper, K.M.; Cala, J.M.; Gin, L.E.; Brownell, S.E. Fear of negative evaluation and student anxiety in community college active-learning science courses. CBE Life Sci. Educ. 2020, 19, ar20. [CrossRef]

48. Barraket, J. Teaching Research Method Using a Student-Centred Approach? Critical Reflections on Practice. J. Univ. Teach. Learn. Pract. 2005, 2, 3.

49. Lobb, H. A student-centred approach to teaching. Agora 2020, 55, 23.

50. Al-Balushi, S.M.; Ambusaidi, A.K.; Al-Balushi, K.A.; Al-Hajri, F.H.; Al-Sinani, M.S. Student-centred and teacher-centred science classrooms as visualized by science teachers and their supervisors. Teach. Teach. Educ. 2020, 89, 103014. [CrossRef]

51. Kember, D. Promoting student-centred forms of learning across an entire university. High. Educ. 2009, 58, 1-13. [CrossRef]

52. Lucisano, P. Fare ricerca con gli insegnanti. I primi risultati dell'indagine nazionale SIRD "Per un confronto sulle modalità di didattica a distanza adottate nelle scuole italiane nel periodo di emergenza COVID-19". Lifelong Lifewide Learn. 2020, 16, 3-25.

53. Gewin, V. Five tips for moving teaching online as COVID-19 takes hold. Nature 2020, 580, 295-296. [CrossRef] [PubMed]

Publisher's Note: MDPI stays neutral with regard to jurisdictional claims in published maps and institutional affiliations.

(C) 2020 by the authors. Licensee MDPI, Basel, Switzerland. This article is an open access article distributed under the terms and conditions of the Creative Commons Attribution (CC BY) license (http://creativecommons.org/licenses/by/4.0/). 